$\xi=-1$

\title{
Total asset prediction of the large Indonesian bank using adaptive artificial neural network back-propagation
}

\author{
Fariyanti $^{1}$, Iskandar ${ }^{2}$, Rheo Malani ${ }^{3}$, Bedi Suprapty ${ }^{3 *}$ \\ ${ }^{1}$ Department of Accounting, State Polytechnic of Samarinda, East Kalimantan, Indonesia \\ ${ }^{2}$ Department of Accounting, Mulawarman University, Samarinda, East Kalimantan, Indonesia \\ ${ }^{3}$ Department of Information Technology, State Polytechnic of Samarinda, East Kalimantan, Indonesia \\ *Corresponding author E-mail: bedirheody@gmail.com
}

\begin{abstract}
The bank is a type of company that acts as the executor of monetary policy and as a guarantor of the stability of the financial system of a country. Total assets are an important aspect for a bank to generate net income. Return on Assets (ROA) is a profitability ratio to measure the ability of a bank in generating profits with all investments owned. This study predicts the total assets of the largest banks in Indonesia, referring to the Indonesia Stock Exchange data from 2005 to 2016. The time series data model used is Autoregressive (AR) model and Multi Input Single Output (MISO) Autoregressive with exogenous input (ARX) model. Adaptive Artificial Neural Network Backpropagation (Adaptive ANN-BP) is used as an approximation model of both models.
\end{abstract}

Keywords: net total assets, net income, ROA, AR model, MISO-ARX model, Adaptive NNBP

\section{Introduction}

Bank has a role as an executor of monetary policy and to maintain the stability of country's financial system. Financial statement analysis is an important part of knowing the company's ability to generate profit. The Cross-Sectional Analysis and Time Series Analysis are commonly used to analyze the financial ratio [1].

The Bank is a financial intermediary institution generally established with the authority to accept deposits of money, lend money, and issue promissory notes or banknotes. The word bank comes from Italian "banca" means a money changer.

There are three types of bank financial ratios, one of which is profitability ratios. This ratio is used to measure the business efficiency and profitability of a bank in a certain period. Return on Asset (ROA) is a profitability ratio to measure a bank's ability to profit from all its investment [1]. Higher ROA indicates the high capital intensity of a bank to its total equity. In this case, can be stated ROA has a positive influence on changes in net income.

A Net income equal to profit and loss is defined as the residual amount of all revenues and gains over all expenses and losses for a specified period. Net income can also be reviewed from the perspective of ROA and ROE (Return on Equity). Higher ROE indicates the higher efficiency level of capital management of a bank. In this case, can be stated ROE has a positive influence on changes in net income.

Total assets refer to the total number of assets owned by a person or entity. An asset is an economic, tangible or intangible source, which can be owned or controlled to produce a value and held by a company to generate a positive economic value. Simply put, an asset is a value of ownership that can be converted into cash. The total asset can be analogized as a standard asset, an asset that does not describe a problem or weakness with respect to principal and interest redemption. In other words, such assets do not carry more than the normal risks attached to the business [1].
Forecasting total assets will be helpful in terms of measuring the ability of a bank to generate profit from all its investments. Forecasting is the activity of predicting or predicting what will happen in the future with a relatively long time. To predict it requires accurate data in the past, so that can be seen prospects of future situations and conditions. Usually, the data in the past is expressed in the form of time series data.

There are many studies that have been done in the area of forecasting. Various methods have been applied to obtain acceptable forecasting results. Time series data modeling becomes very important to guarantee the results. The statistical method is the most conventional method used to perform various forecasting activities through time series data modeling.

The ARIMA (Auto Regressive Integrated Moving Average) [2-4] model has been used to predict the volatility of the stock market industry. The results have also been compared with the ARIMAWT (Wavelet Transform) model combination. This research has been conducted in [5]. The NPA (Non-Performing Asset) time series data model forecasting on selected public sector banks with semiparametric approach has been done in [1]. ARIMA model and Box Jenkins methodology have been used for forecasting of bank credit to public and private sector in [6]. Research on the mapping of parametric and nonparametric statistics in data analysis in marketing research has also been done in [7].

To improve forecasting results, many researchers have applied machine learning methods in some forecasting activities. Machine learning methods have been used independently, combined with inter-methods, even combined with various statistical methods such as in [8-22].

In this study, the prediction of the total asset is based on the time series data modeling using AR and MISO-ARX models. The MISO-ARX model uses only two independent variables obtained from the equation of ROA. Both models are implemented by using the ANN-BP. The net structure is trained using adaptive learning method. The trained net structure is then used to predict total as- 
sets in the next year. The aim of this study is to compare both ANN based AR and MISO-ARX model to conduct those prediction activities.

\section{Materials and Methods}

\subsection{AR and ARX model}

The AR (Auto-Regressive) model is one of the ARIMA BoxJenkins model groups, which is used to predict the following data based on previous data. While the ARX (AR with external input) model is an AR model with an external input occurring at the same time as the previous data.

The general structure of AR model expressed by:

$$
y(t)=-a_{1} y(t-1)-\ldots-a_{n} y(t-n)+e(t)
$$

The variable $a_{1}$ is a constant, $n$ is order number of the system, and $e(t)$ is a white noise. The Eq. (1) can be decomposed into the following [23]:

$$
\begin{aligned}
y(t) & =\left(a_{1} q^{-1}+\ldots+a_{n} q^{-n}\right) y(t)+e(t) \\
& =-\left(\sum_{i=1}^{n} a_{i} q^{-i}\right) y(t)+e(t) \\
& =A\left(q^{-1}\right) y(t)+e(t)
\end{aligned}
$$

In Eq. (2), $q^{-1}$ is the delay operator and $A\left(q^{-1}\right)$ is the polynomial to be estimated. Eq. (2) is illustrated in Figure 1.

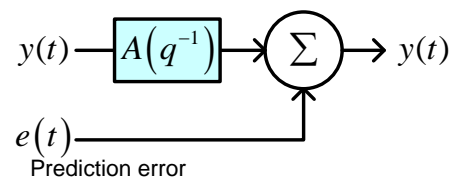

Fig. 1: AR model

The ARX model in a compact form is declared as:

$$
y(t)=A\left(q^{-1}\right) y(t)+B\left(q^{-1}\right) x(t)+e(t)
$$

The variables $A\left(q^{-1}\right)$ and $B\left(q^{-1}\right)$ are polynomials to be estimated. Eq. (3) is illustrated in Figure 2.

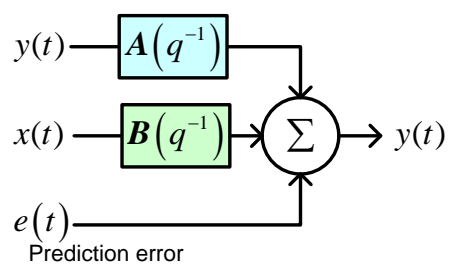

Fig. 2: ARX model

In the same way, the MISO-ARX model is declared as:

$$
\begin{aligned}
y(t)= & A\left(q^{-1}\right) y(t)+B_{1}\left(q^{-1}\right) x_{1}(t) \\
& +\ldots+B_{m}\left(q^{-1}\right) x_{m}(t)+e(t)
\end{aligned}
$$

Many methods can be used to estimate all weights on polynomials, either AR or ARX, as has been done in [24-26]. Some of them are like OLS (Ordinary Least Square) and GARCH (Generalized AutoRegressive Conditional Heteroskedasticity). OLS is based on the concept of pure regression analysis where each regression coefficient needs to be tested using t-Test to meet established standard errors. The GARCH test is usually used to test for the possibility of two variables being associated with volatility or the existence of a deviation pattern from the OLS model. To simplify the problem, in this study FFNN is used as an approximation model, for both AR and ARX models, and expressed by: $A R$ model:

$$
y(t)=N_{f f}\left(A\left(q^{-1}\right) y(t)\right)+e(t)
$$

MISO-ARX model:

$y(t)=N_{f f}\left(\begin{array}{l}A\left(q^{-1}\right) y(t), B_{1}\left(q^{-1}\right) x_{1}(t), \\ \ldots, B_{m}\left(q^{-1}\right) x_{m}(t)\end{array}\right)+e(t)$

By training $N_{f f}(\cdot)$ such that $e(t) \rightarrow 0$ then $N_{f f}(\cdot) \rightarrow y(t)$. In its implementation, $e(t)$ is set as small as possible.

The FFNN architecture used is shown in Figure 3. ANN-BP doing backpropagation to fix the weight of each layer such that to achieve appointed target error [23], as shown in Figure 4.

The ANN-BP is not always able to achieve the target error that has been specified. This can be caused by various conditions, one of which is the pattern of training data used. In this case, we need a method that is able to force ANN-BP to achieve the target error that has been determined without having to analyze the pattern of training data used. The adaptive ANN-BP is ANN-BP which uses adaptive learning method in terms of weighted adjustment of each layer. Adaptive weight adjustment is performed by random selection of both the weight of the input layer and the weight of the hidden layer.

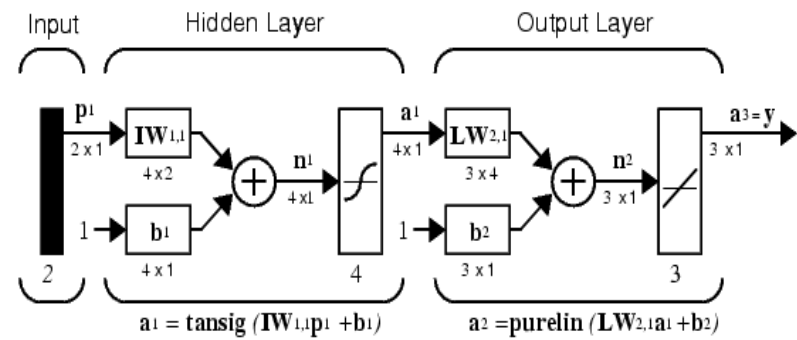

Fig. 3: FFNN architecture

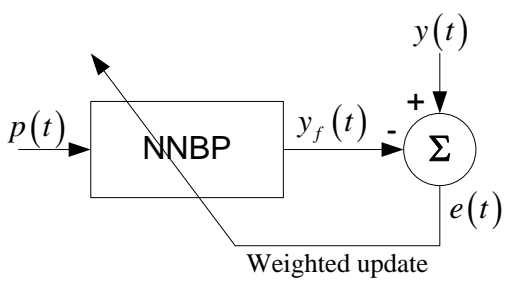

Fig. 4: Back-propagation training

The selected weights are updated by adding a very small random number. The network weights are updated adaptively which conducted continuously to achieve the target error. The training of adaptive ANN-BP model is shown in Figure 5, whereas the algorithm as shown in Figure 6.

The variable $m$ is the number of the input system.

\subsection{ANN-based AR and MISO-ARX model}




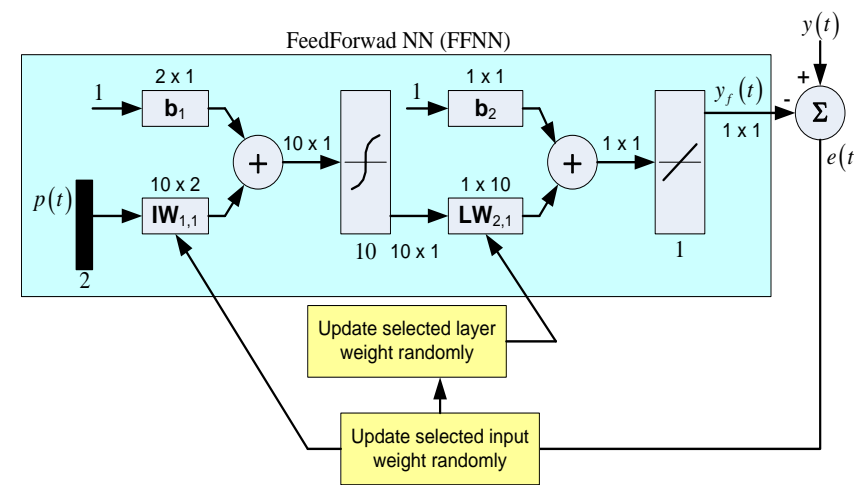

Fig. 5: Adaptive learning model

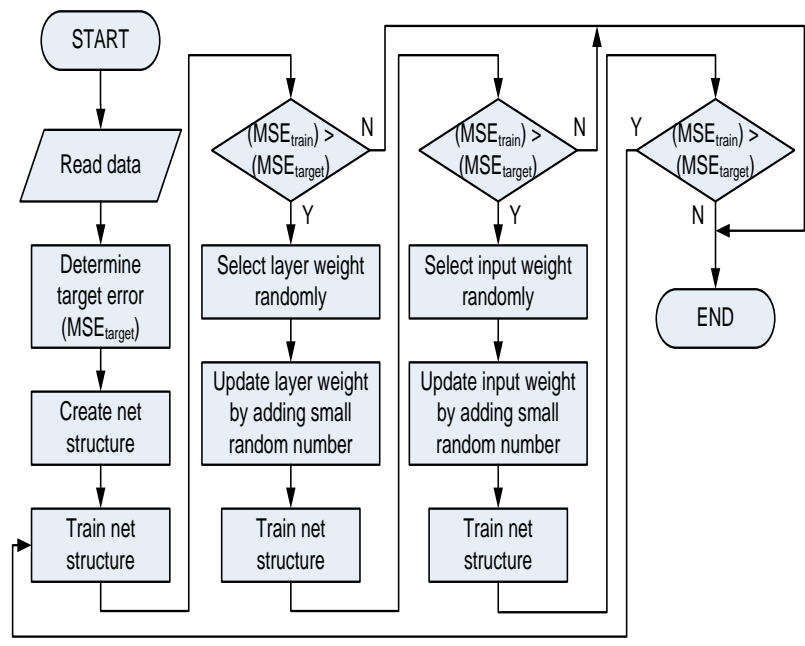

Fig. 6: The algorithm of adaptive ANN-BP

The net structure as shown in Figure 1 uses 10 hidden neurons whereas target error $e(t)=10^{-5}$. The activation function used in those net is log-sigmoid expressed by:

$$
f(x)=\frac{1}{1+e^{-x}}
$$

This function maps all forward propagation results of each layer net to a value in the range $(0 \ldots 1)$. For this reason, all datasets used as training data need to be normalized to be within that range using the following formula:

$$
x_{n}(i)=\frac{x(i)}{\max (X)+\min (X)}
$$

The variable $x(i)$ is the data within the dataset of $X$.

The performance functions of training results using MSE (Mean Squared Error) which is declared as:

$$
M S E=\frac{1}{N} \sum_{i=1}^{N}\left(y\left(t_{i}\right)-y_{f f}\left(t_{i}\right)\right)^{2}
$$

In Eq. (10), $N$ is the number of the training data, $y\left(t_{i}\right)$ is the $i$ th training target, and $y_{f f}\left(t_{i}\right)$ is the $i$ th output of ANN-BP.

The adaptive ANN-BP implementation is done by using MATLAB programming tool. The performance function of trained net structure validation using APE (Absolute Percentage Error) expressed by:
$A P E=\left(1-\frac{\mid \text { actual }- \text { prediction } \mid}{\text { actual }}\right) \times 100 \%$

\subsection{The proposed method implementation}

The selected bank is BRI bank. All of the data are obtained from Indonesia Stock Exchange IDX LQ45 in 2005 - 2016 [27-31] in the form of total asset, net income, and ROA, as seen in Table 1. Since ROA=Net Income $\times(1 /$ Total Assets $) \times 100 \%$ then total assets can be declared as Total Assets=Net Income $\times(1 / R O A)$. This formula is used to model the time series data, both AR and MISOAR models.

Case 1: Time series data modeling by using AR model The time series data model using the $2^{\text {nd }}$ order AR model can be declared as:

$$
N_{f f}(y(t-1), y(t-2)) \rightarrow y(t)
$$

The variables are:

$y(t-2):$ The total assets from the year of 2005-2014.

$y(t-1) \quad:$ The total assets from the year 2006-2015.

Both variables are used as training data input.

$y(t) \quad$ : The total assets from the year 2007-2016 used as the training target.

Table 1: Financial Data of BRI

\begin{tabular}{|c|c|r|r|}
\hline Year & $\begin{array}{c}\text { Total Asset } \\
\text { (millions) }\end{array}$ & Net Income (millions) & ROA (\%) \\
\hline 2005 & $234,339,877$ & $5,378,647$ & 2.2952 \\
\hline 2006 & $234,280,433$ & $5,394,383$ & 2.3025 \\
\hline 2007 & $236,729,948$ & $5,549,449$ & 2.3442 \\
\hline 2008 & $246,076,896$ & $5,958,368$ & 2.4213 \\
\hline 2009 & $316,947,029$ & $7,308,292$ & 2.3058 \\
\hline 2010 & $404,285,602$ & $11,472,385$ & 2.8377 \\
\hline 2011 & $469,899,284$ & $15,087,996$ & 3.2109 \\
\hline 2012 & $551,336,790$ & $18,687,380$ & 3.3895 \\
\hline 2013 & $626,182,926$ & $21,354,330$ & 3.4102 \\
\hline 2014 & $801,955,021$ & $24,253,845$ & 3.0243 \\
\hline 2015 & $878,426,312$ & $25,410,788$ & 2.8928 \\
\hline 2016 & $1,003,644,426$ & $26,227,991$ & 2.6133 \\
\hline
\end{tabular}

Case 2: Time series data modeling by using MISO-ARX model The time series data model using the 2nd order MISO-ARX model can be declared as:

$$
N_{f f}\left(\begin{array}{c}
y(t-1), y(t-2), x_{1}(t-1), \\
x_{1}(t-2), x_{2}(t-1), x_{2}(t-2)
\end{array}\right) \rightarrow y(t)
$$

The variables are:

$$
\begin{aligned}
& x_{1}(t-2): \text { The net income from the year 2005-2014. } \\
& x_{1}(t-1): \text { The net income from the year 2006-2015. } \\
& x_{2}(t-2): \text { 1/ROA from the year 2005-2014. } \\
& x_{2}(t-1): \text { 1/ROA from the year 2006-2015. }
\end{aligned}
$$

All of them are used as training data input.

The training results of adaptive ANN-BP are shown in Figure 7 (a) for case 1 and Figure 7 (b) for case 2.

From the training result, it can be concluded that adaptive ANN-BP has been able to reach the target of error which has been determined $\left(e(t)=10^{-5}\right)$. The training result of ANNbased AR model yields MSE $=8.724 \times 10^{-6}$, whereas ANN-based MISO-ARX model yields MSE $=9.994 \times 10^{-6}$. 


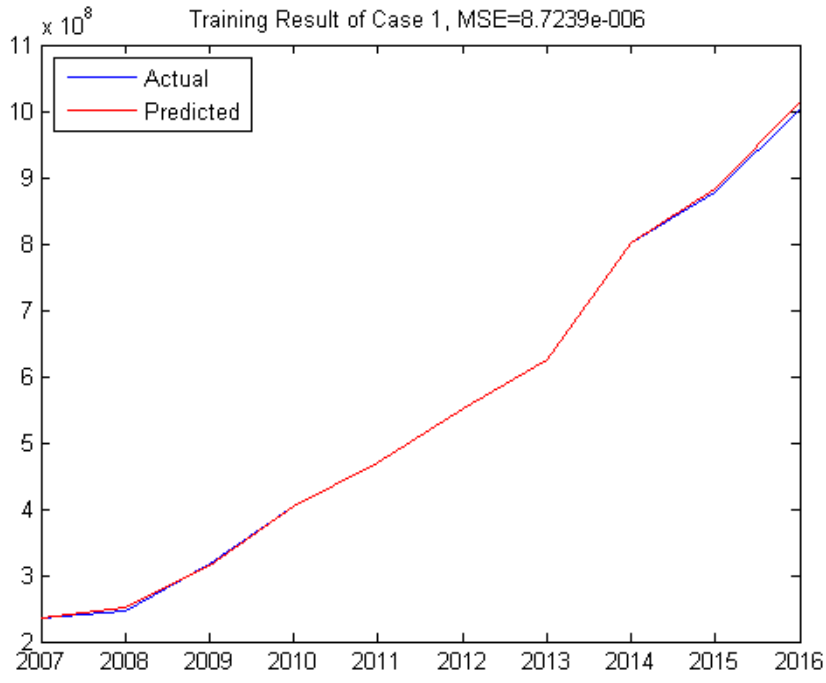

(a)

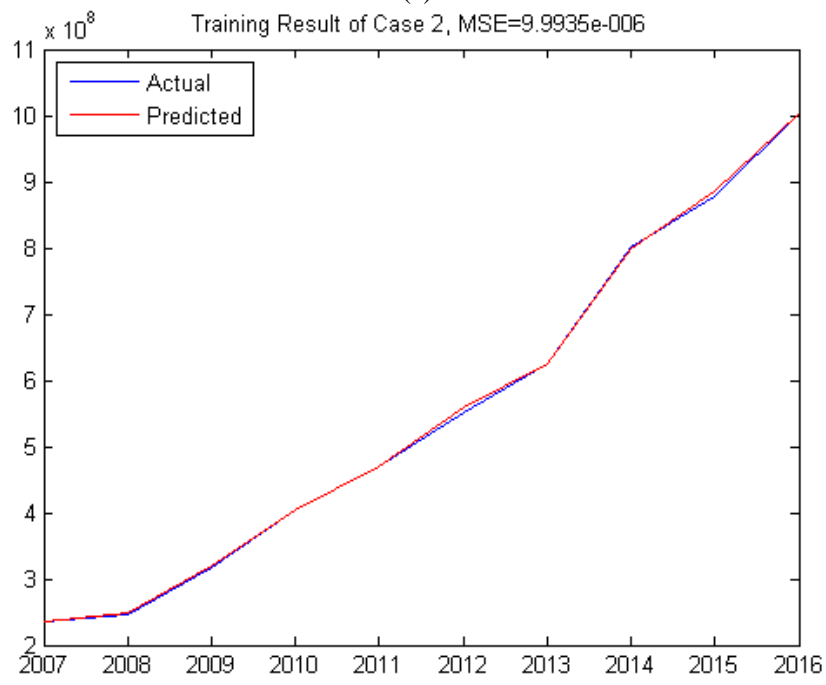

(b)

Fig. 7: The adaptive ANN-BP training results: (a) Case 1, (b) Case 2

\section{Results and discussions}

Case 1:

The net structure that has been trained then used to predict the total assets in the year 2017. Since:

$$
N_{f f}(y(t-1), y(t-2)) \rightarrow y(t)
$$

Then for the next year can be declared as:

$$
N_{f f}(y(t), y(t-1)) \rightarrow y(t+1)
$$

The prediction result of 2017 obtained the total assets of Rp. $1,022,855,590,000$. Because the BRI bank has actual total assets of Rp. 954.2 trillion in the year 2017, then the performance of predicted results is:

$$
A P E_{A R}=\left(1-\frac{|954.2-1,022.9|}{954.2}\right) \times 100 \%=92.8 \%
$$

Case 2:

Using the same manner, then:

$$
N_{f f}\left(\begin{array}{l}
y(t), y(t-1), x_{1}(t), \\
x_{1}(t-1), x_{2}(t), x_{2}(t-1)
\end{array}\right) \rightarrow y(t+1)
$$

The prediction result of 2017 obtained the total assets of Rp. $960,204,617,000$. The performance of predicted results is:

$$
A P E_{\text {MISO-ARX }}=\left(1-\frac{|954.2-960.9|}{954.2}\right) \times 100 \%=99.37 \%
$$

From those results obtained that prediction model by using ANNbased MISO-ARX is better than ANN-based AR model.

\section{Conclusions}

The adaptive ANN-BP has been implemented to anticipate the inability of the ANN-BP to achieve target error in various conditions. From the research obtained that the best prediction result is using MISO-ARX model which has the performance of $99.37 \%$.

Future work is how to improve the performance of the proposed method, especially in terms of minimizing the number of iterations.

\section{Acknowledgement}

The authors would like to express their heartfelt thanks to The Modern Computing Research Center, Department of Information Technology, State Polytechnic of Samarinda, for providing all their support.

\section{References}

[1] G. Bandyopadhyay, "Modeling NPA Time Series Data in Selected Public Sector Banks in India with Semi Parametric Approach," International Journal of Scientific \& Engineering Research (IJSER), vol. 4, pp. 1876-1889, (2013).

[2] A. S. Ahmar, S. Guritno, A. Rahman, I. Minggi, M. Arif Tiro, M. Kasim Aidid, et al., "Modeling Data Containing Outliers using ARIMA Additive Outlier (ARIMA-AO)," Journal of Physics: Conf. Series, vol. 954, 2018.

[3] A. Rahman and A. S. Ahmar, "Forecasting of primary energy consumption data in the United States: A comparison between ARIMA and Holter-Winters models," in AIP Conference Proceedings vol. 1885, ed, 2017.

[4] A. S. Ahmar, "A Comparison of $\alpha$-Sutte Indicator and ARIMA Methods in Renewable Energy Forecasting in Indonesia," International Journal of Engineering \& Technology, vol. 7, pp. 9-11, 2018.

[5] S. Al Wadi, "Improving Volatility Risk Forecasting Accuracy in Industry Sector," International Journal of Mathematics and Mathematical Sciences, vol. 2017, pp. 1-6, (2017).

[6] A. Noreen, R. Asif, S. Nisar, and N. Qayyum, "Model Building and Forecasting of Bank Credit to Public and Private Sector," Universal Journal of Accounting and Finance, vol. 5, pp. 73-77, (2017).

[7] E. F. O., "The Implications of Parametric and Non-Parametric Statistics in Data Analysis in Marketing Research," International Journal of Humanities and Social Science vol. 5, pp. 74-83, (2015).

[8] A. Dingli and K. S. Fournier, "Financial Time Series Forecasting - A Machine Learning Approach," Machine Learning and Applications: An International Journal, vol. 4, pp. 11-27, (2017).

[9] P. Enyindah and O. U. C., "A Neural Network Approach to Financial Forecasting," International Journal of Computer Applications (IJCA), vol. 135, pp. 28-32, (2016).

[10] E. U. A. Gaffar, "Prediction of Regional Economic Growth in East Kalimantan using Genetic Algorithm," International Journal of Computing and Informatics (IJCANDI), vol. 1, pp. 58-67, May, (2016).

[11] A. Graham and E. P. Mishra, "Time series analysis model to forecast rainfall for Allahabad region," Journal of Pharmacognosy and Phytochemistry, vol. 6, pp. 1418-1421, (2017).

[12] C.-F. Huang and H.-C. Li, "An Evolutionary Method for Financial Forecasting in Microscopic High-Speed Trading Environment," Computational Intelligence and Neuroscience, vol. 2017, pp. 1-18, (2017).

[13] M. Khairalla, X. Ning, and N. T. AL-Jallad, "Hybrid Forecasting Scheme for Financial Time-Series Data using Neural Network and Statistical Methods," (IJACSA) International Journal of Advanced Computer Science and Applications, vol. 8, pp. 319327, (2017).

[14] S. Mukherjee and S. Galeshchuk, "Deep Learning for Predictions in Emerging Currency Markets," pp. 681-686, 2017.

[15] M. B. Patel and S. R. Yalamalle, "Stock Price Prediction Using Artificial Neural Network," International Journal of Innovative Research in Science, Engineering and Technology (IJIRSET), vol. 3, pp. 13755-13762, (2014).

[16] L. D. Persio and O. Honchar, "Recurrent neural networks approach to the financial forecast of Google assets," 
INTERNATIONAL JOURNAL OF MATHEMATICS AND COMPUTERS IN SIMULATION vol. 11, pp. 7-13, (2017).

[17] R. Pradhan, "Z Score Estimation for Indian Banking Sector," International Journal of Trade, Economics and Finance, vol. 5, pp. 516-520, (2014).

[18] B. Prasad and K. Molugaram, "Development of mode choice models of a trip maker for Hyderabad metropolitan city," International Journal of Engineering \& Technology (IJET), vol. 7, pp. 1-7, (2018).

[19] J. Vrbka, "Predicting Future GDP Development by Means of Artificial Intelligence," Littera Scripta, vol. 9, pp. 154-167, (2016).

[20] T. Wang, "Forecast of Economic Growth by Time Series and Scenario Planning Method-A Case Study of Shenzhen," Modern Economy, vol. 07, pp. 212-222, (2016).

[21] K. Yang and S. Liu, "A Hybrid Model for Short-Term Load Forecasting Based on Non-Parametric Error Correction," International Journal of Multimedia and Ubiquitous Engineering, vol. 10, pp. 329-340, (2015).

[22] Haviluddin and R. Alfred, "A Genetic-Based Backpropagation Neural Network for Forecasting in Time-Series Data," in The 2015 International Conference on Science in Information Technology (ICSITech 2015), Yogyakarta, Indonesia, 2015, pp. xxx-Xxx.

[23] M. H. Beale, M. T. Hagan, and H. B. Demuth. ((2015)). Neural Network Toolbox ${ }^{T M}$ MATLAB R2015a-User's Guide.
[24] A. A. Abdurehman and S. Hacilar, "The Relationship between Exchange Rate and Inflation: An Empirical Study of Turkey," International Journal of Economics and Financial Issues (IJEFI), vol. 6, pp. 1454-1459, (2016).

[25] K. Kwon, W.-S. Cho, and J. Na, "ARIMAX and ARX Models with Social Media Information to Predict Unemployment Rate," Journal of Advanced Management Science, pp. 401-404, (2016).

[26] F. Piltan, S. TayebiHaghighi, and N. B. Sulaiman, "Comparative Study between ARX and ARMAX System Identification," International Journal of Intelligent Systems and Applications, vol. 9, pp. 25-34, (2017)

[27] I. S. Exchange, "LQ45 Index Constituents for the period of February - July 2013," I. S. Exchange, Ed., ed: Indonesia Stock Exchange, (2013).

[28] I. S. Exchange, "LQ45 Index Constituents for the period of February - July 2014," R. a. D. D.-I. S. Exchange, Ed., ed: Indonesia Stock Exchange, (2014).

[29] I. S. Exchange, "LQ45 Index Constituents for the period of February - July 2015," I. S. Exchange, Ed., ed: Indonesia Stock Exchange, (2015).

[30] I. S. Exchange, "LQ45 Index Constituents for the period of February - July 2016," I. S. Exchange, Ed., ed: Indonesia Stock Exchange, (2016).

[31] I. S. Exchange, "LQ45 Index Constituents for the period of February - July 2017," I. S. Exchange, Ed., ed: Indonesia Stock Exchange, (2017). 